\title{
Pathogenesis of growth failure and partial reversal with gene therapy in murine and canine Glycogen Storage Disease type Ia
}

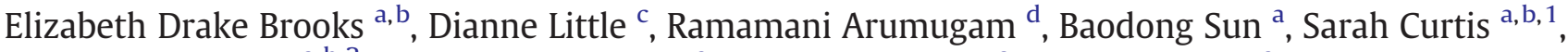 \\ Amanda DeMaster ${ }^{\text {a,b,2 }}$, Michael Maranzano a , Mark W. Jackson ${ }^{\text {e }}$, Priya Kishnani a , \\ Michael S. Freemark ${ }^{\mathrm{d}}$, Dwight D. Koeberl ${ }^{\mathrm{a}, *}$ \\ a Division of Medical Genetics, Department of Pediatrics, Duke University Medical Center, Durham, NC, USA \\ ${ }^{\mathrm{b}}$ Division of Laboratory Animal Resources, Duke University Medical Center, Durham, NC, USA \\ c Orthopaedic Research Laboratories, Department of Orthopaedic Surgery, Duke University Medical Center, Durham, NC, USA \\ d Division of Endocrinology and Diabetes, Department of Pediatrics, Duke University Medical Center, Durham, NC, USA \\ e Institute of Biodiversity, Animal Health and Comparative Medicine, University of Glasgow, Scotland, UK
}

\section{A R T I C L E I N F O}

\section{Article history:}

Received 12 February 2013

Received in revised form 29 March 2013

Accepted 29 March 2013

Available online 6 April 2013

\section{Keywords:}

Glycogen Storage Disease la

Growth failure

Gene therapy

Glucose-6-phosphatase

Adeno-associated virus

IGF 1

\begin{abstract}
A B S T R A C T
Glycogen Storage Disease type la (GSD-Ia) in humans frequently causes delayed bone maturation, decrease in final adult height, and decreased growth velocity. This study evaluates the pathogenesis of growth failure and the effect of gene therapy on growth in GSD-Ia affected dogs and mice. Here we found that homozygous G6pase (-/-) mice with GSD-Ia have normal growth hormone (GH) levels in response to hypoglycemia, decreased insulin-like growth factor (IGF) 1 levels, and attenuated weight gain following administration of GH. Expression of hepatic GH receptor and IGF 1 mRNAs and hepatic STAT5 (phospho Y694) protein levels are reduced prior to and after GH administration, indicating GH resistance. However, restoration of G6Pase expression in the liver by treatment with adeno-associated virus 8 pseudotyped vector expressing G6Pase (AAV2/8-G6Pase) corrected body weight, but failed to normalize plasma IGF 1 in G6pase $(-/-)$ mice. Untreated G6pase (-/-) mice also demonstrated severe delay of growth plate ossification at 12 days of age; those treated with AAV2/8-G6Pase at 14 days of age demonstrated skeletal dysplasia and limb shortening when analyzed radiographically at 6 months of age, in spite of apparent metabolic correction. Moreover, gene therapy with AAV2/9-G6Pase only partially corrected growth in GSD-la affected dogs as detected by weight and bone measurements and serum IGF 1 concentrations were persistently low in treated dogs. We also found that heterozygous GSD-Ia carrier dogs had decreased serum IGF 1, adult body weights and bone dimensions compared to wild-type littermates. In sum, these findings suggest that growth failure in GSD-la results, at least in part, from hepatic GH resistance. In addition, gene therapy improved growth in addition to promoting long-term survival in dogs and mice with GSD-Ia.
\end{abstract}

(c) 2013 Elsevier Inc. All rights reserved.

\section{Introduction}

Type Ia Glycogen Storage Disease (GSD-la, also known as von Gierke disease; MIM +232200) is an autosomal recessive disorder caused by a deficiency of glucose-6-phosphatase (G6Pase). This

\footnotetext{
Abbreviations: AAV, Adeno-associated virus; AAV-G6Pase, Adeno-associated viral vector expressing glucose-6-phosphatase; BCS, Body Condition Score; BMI, Body Mass Index; FASN, Fatty Acid Synthase; G6Pase, Glucose 6-phosphatase; GSD-Ia, Glycogen Storage Disease Ia; GH, Growth Hormone; IGF, Insulin-like Growth Factor; PCR, Polymerase Chain Reaction; PRLR-L, Prolactin Receptor; SDS, Standard Deviation Score; STAT5, Signal Transducer and Activator of Transcription; WT, Wild-type.

* Corresponding author at: DUMC Box 103856, Duke University Medical Center, Durham, NC 27710, USA. Fax: + 19196840983.

E-mail address: dwight.koeberl@duke.edu (D.D. Koeberl).

1 Current address: Rehoboth Beach Animal Hospital, Rehoboth Beach, DE, USA.

2 Current address: East Lincoln Animal Hospital, Denver, NC, USA.
}

deficiency results in a number of metabolic problems such as, hypoglycemia and lactic acidosis which can lead to renal and/or hepatic disease, pancreatitis, osteopenia, hepatic adenomas or hepatocellular carcinoma and growth failure in older children and adults [1,2].

Of humans affected with GSD-Ia, 43\%-59\% exhibit incongruent bone age, $10-35 \%$ short stature $[3,4]$, and $14 \%$ decreased growth velocity $[3,5]$. There are multiple hypotheses regarding the exact cause of growth impairment, including chronic lactic acidemia, recurrent or persistent hypoglycemia, dietary restrictions, growth hormone $(\mathrm{GH})$ and/or insulin-like growth factor (IGF) resistance, hypoinsulinemia, hypercortisolemia and negative calcium balance [3,5]. Nevertheless, the pathogenesis of growth failure in GSD-Ia is poorly understood.

Several treatments have been used to improve growth of patients with GSD-Ia with variable success, but generally there are positive correlations between biochemical control of the disease, growth rate and ultimate height $[2,6]$. Dietary treatment with uncooked corn starch or 
nasogastric tube feeding improves metabolic control and increases survival and can partially prevent growth retardation, especially if started early in life [7,8]. Further, height standard deviation score (SDS) in children with GSD-Ia correlates with circulating IGF 2 and compliance with dietary therapy; but is not associated with a deficiency of GH [3]. GH replacement therapy and diazoxide therapy improved height in some cases $[9,10]$. Liver transplantation has been shown to rescue growth in the majority (8/11) of young GSD-Ia patients when recorded posttransplantation [11-13]. Inconsistent success in treatment of growth retardation and other long term complications through empirical treatment suggests that there is an unmet clinical need for therapy that consistently improves metabolic control of GSD-la patients to prevent long term complications.

One such treatment under evaluation is gene therapy. Adenoassociated viral vector expressing glucose-6-phosphatase (AAV-G6Pase) to promote expression of G6Pase in the liver and kidneys has been evaluated in canine and murine GSD-la models $[14,15]$. Animals treated with AAV-G6Pase have significantly increased survival times, normal plasma lactate and glucose, and decreased hepatic glycogen deposition and vacuolization compared to untreated GSD-la affected dogs or mice [14-17]. A single treatment can maintain metabolic homeostasis lifelong in AAV-G6Pase-treated mice, but metabolic control wanes over time in AAV-G6Pase vector-treated dogs [16,18]. However, GSD-Ia affected dogs receiving 2-4 treatments of AAV-G6Pase therapy with different serotypes thrive and survive to greater than 60 months of age $[14,17]$.

The goals of this study were to elucidate the pathogenesis of growth failure in GSD-la affected mice and dogs and to evaluate the effects of treatment with AAV vector-mediated therapy on growth in GSD-la affected mice and dogs. We used a G6Pase knockout [G6pase $(-/-)$ ] mouse model to clarify the role of GH signaling in the growth failure associated with GSD-Ia. We then analyzed weight gain, bone development and IGF 1 concentrations in G6pase (-/-) mice treated with an adeno-associated virus (AAV) vector that expresses mouse G6Pase. We evaluated bodyweight, serum IGF 1 concentrations and bone measurements in AAV-G6Pase vector-treated GSD-Ia affected dogs, GSD-Ia affected dogs only receiving dietary therapy and their unaffected wild-type and GSD-Ia heterozygous carrier littermates. Previous studies from this lab showed that this vector partially reverses G6Pase deficiency and reduces glycogen stores to near-normal levels while preventing hypoglycemia during fasting for a near normal life span of mice and dogs [14,16]. Dog data presented were from dogs in which survival, plasma glucose and lactate, hepatic complications and vector efficacy have recently been reported by DeMaster et al. [14].

\section{Materials and methods}

\subsection{Murine care and treatment}

All parts of this study were performed according to the guidelines and oversight of the Duke University and North Carolina State University Institutional Animal Care and Use Committees. G6pase $(+/-)$ mice were provided by Dr. Janice Chou (National Institutes of Health) and bred to produce homozygous, affected G6pase (-/-) offspring. Affected genotype was confirmed by polymerase chain reaction (PCR) analysis of tail DNA with primers within and flanking the neo gene insertion in the G6Pase gene as described [19]. Livers were collected from mice at $13+/-1$ days of age and frozen on dry ice for GH-related quantification assays and Western blotting (Figs. 1, 2).

Affected G6pase (-/-) mice were small with prominent hepatomegaly at 7 days of age, whereas unaffected carrier $(+/-)$ and wild-type $(+/+)$ mice appeared grossly normal. Groups of G6pase $(-/-)$ and unaffected [both G6pase $(+/+)$ and $(+/-)]$ mice received daily glucose injections and were treated with GH daily for 7 days before the liver was collected for RT-PCR quantification. Unaffected mice
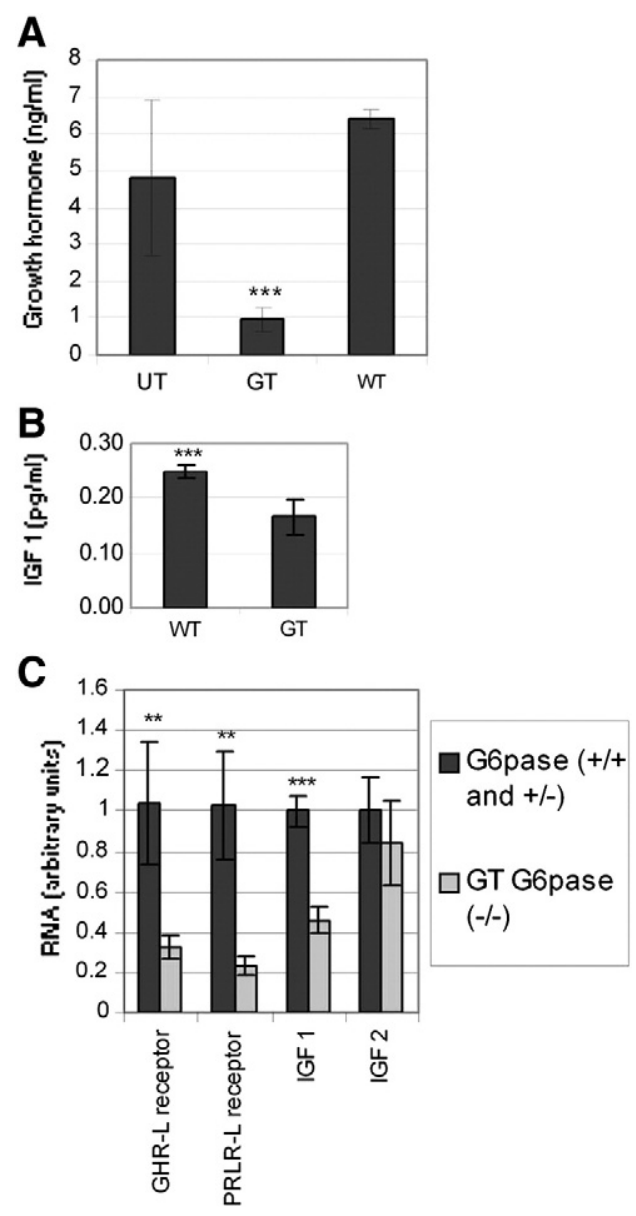

Fig. 1. Decreased GH, IGF 1, and hepatic receptors for GH, prolactin and IGF 1 in G6pase $(-/-)$ mice. (A) Randomly sampled plasma growth hormone in G6pase (-/-) mice, either untreated (UT; $n=3$ ) or glucose treated (GT; $n=4)$ and for G6pase $(+/+)$ littermates (WT; $\mathrm{n}=3$ ). (B) Plasma IGF 1 for WT mice and for GT G6pase $(-/-)$ mice at 2 weeks of age ( $n=3$ in each group). (C) Realtime RT-PCR analysis of liver RNA from $13+/-1$-day-old G6pase $(-/-)$ and unaffected G6pase $(+/+$ and $+/-)$ littermates for the GH receptor (GHR-L) and prolactin receptor (PRLR-L) ( $n=4$ in each group), and for IGF 1 and IGF 2 RNAs ( $n=3$ for each group) in the liver of GT G6pase (-/-) and WT mice, units are normalized to $\beta$-actin. Mean $+/-$ standard deviation shown. ${ }^{* *}=\mathrm{p}<0.01,{ }^{* * *}=\mathrm{p}<0.001$ (as determined by two-tailed homoscedastic Student's $t$-test).

were identified by day 3 of life by the absence of hepatomegaly, and genotype was confirmed for all mice (not shown). G6pase $(+/+)$ and $(+/-)$ mice were grouped together as normal controls. Initially, groups of 4 affected and unaffected mice were treated with $10 \mu \mathrm{g}$ GH injected subcutaneously each morning for 7 days; later another 4 affected and unaffected mice received $25 \mu \mathrm{g}$ daily in an equivalent manner. Ovine $\mathrm{GH}$ was dissolved in $10 \mathrm{ml} \mathrm{PBS} / 10 \%$ dextrose, and mice were injected subcutaneously with $100 \mu \mathrm{l} /$ day for 7 days, starting at 7 days of age. The responses for the two dosages were equivalent, and therefore results were pooled for the two GH treatments.

The impact of hepatic G6Pase deficiency on growth was investigated further by assessing weight gain and plasma IGF 1 concentrations in G6pase (-/-) mice following treatment with an adeno-associated virus (AAV) vector expressing human G6Pase $\left(1 \times 10^{13}\right.$ vector particles/ $\mathrm{kg}$ body weight) at 2 weeks of age (Fig. 3 ). The vector was pseudotyped as serotype 8 to increase tropism for the liver (AAV2/ 8-G6Pase).

\subsection{Canine care and treatment}

All puppies were monitored every 3 to $4 \mathrm{~h}$ for the first week of life to ensure that they were gaining weight and nursing appropriately. If 
A

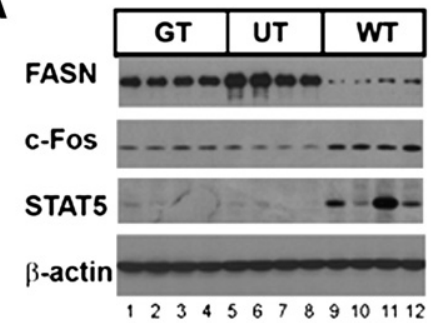

B
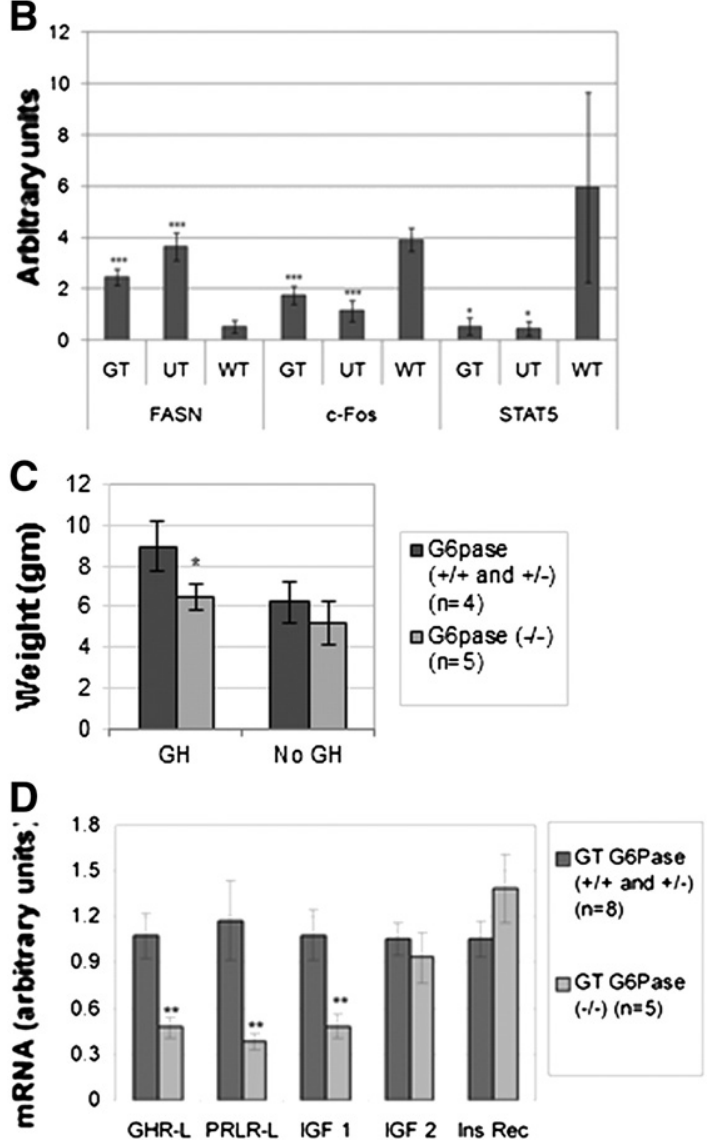

Fig. 2. GH signaling pathway in G6pase (-/-) liver.(A) Western blot detection of fatty acid synthase (FASN), c-Fos, and STAT5 in glucose-treated (GT)G6pase $(-/-)$ mouse and G6pase $(+/+)$ mouse (WT) liver at $13+/-1$ days of age. Each lane represents an individual mouse. (B) Quantification of the indicated proteins by densitometry of Western blot images, normalized to $\beta$-actin. The normalized signals for GT, UT, and WT mouse liver are shown (mean $+/-\mathrm{SD}$ ). (C) Body weight at 10 days of age for $\mathrm{GH}$ treated and untreated mice. Groups were unaffected, (G6pase $(+/-)$ and G6pase $(+/+),(n=4)$ and affected, G6pase $(-/-),(n=5)$ mice. (D) Realtime RT-PCR analysis of liver RNA from $13+/-1$-day-old G6pase $(-/-)(\mathrm{n}=8)$ and both G6pase $(+/-)$ and G6pase $(+/+)$ mice $(n=8)$ following glucose and GH treatment (GT) for growth hormone receptor (GHR-L), prolactin receptor (PRLR-L), IGF 1, IGF 2, and insulin receptor (Ins Rec) RNA ( $\mathrm{n}=4$ for each group), normalized to $\beta$-actin. Half of the mice in each group were injected with $10 \mu \mathrm{g} \mathrm{GH}$ for 7 days, and half of the mice were treated similarly with $25 \mu \mathrm{g}$ daily. The responses for the two dosages were equivalent, and therefore results were pooled for the two GH treatments. ${ }^{*}=p<0.05$ ${ }^{* *}=\mathrm{p}<0.01,{ }^{* * *}=\mathrm{p}<0.001$ (as determined by two-tailed homoscedastic Student's $t$-test) for the comparisons of G6pase (-/-) mice with normal, WT or with unaffected mice. The latter group of unaffected mice included both G6pase (+/-) and G6pase (+/+) mice (see Materials and methods for further information).

they were not gaining weight, bottle or tube feeding with standard milk replacement therapy $(40-100 \mathrm{mg} / \mathrm{g} / \mathrm{day})$ was used in conjunction with dextrose therapy to control hypoglycemia. GSD-la affected puppies were identified by genotyping as previously described by Kishnani et al. [20] and administered an AAV serotype 2 vector pseudotyped as AAV9 expressing human G6Pase (AAV2/9-G6Pase)
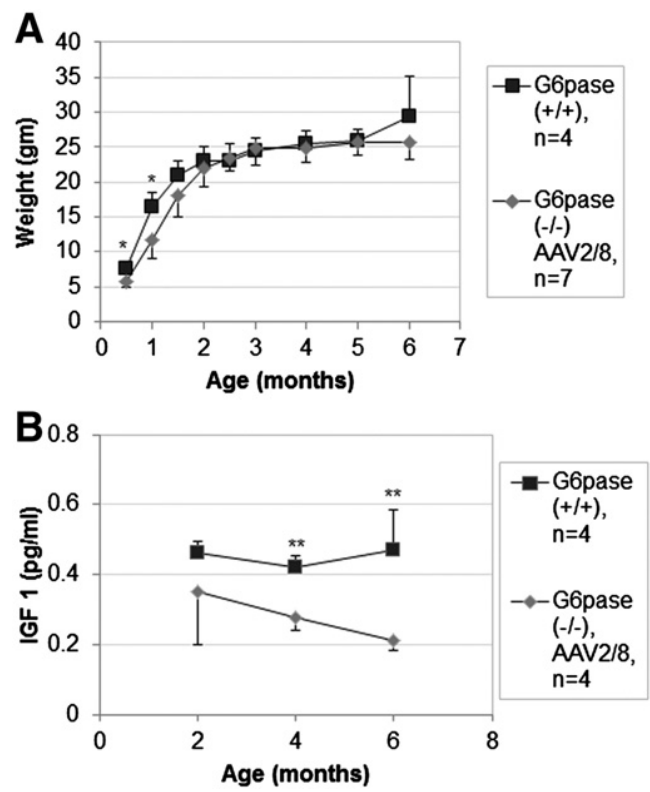

Fig. 3. Growth and IGF 1 in G6pase (-/-) mice following AAV2/9-G6Pase vector administration. Affected mice did not survive until 1 month of age unless the AAV vector was administered. (A) Weight of G6pase $(+/+)$ mice $(n=4)$ and G6pase $(-/-)$ mice $(n=7)$ following administration of the AAV2/8-G6Pase vector $\left(1 \times 10^{13}\right.$ vector particles $/ \mathrm{kg}$ body weight) at 2 weeks of age. (B) Plasma IGF 1 for G6pase $(+/+)$ and G6pase $(-/-)$ mice ( $\mathrm{n}=4$ in each group), either untreated or following AAV2/8-G6Pase vector administration, respectively. ${ }^{*}=\mathrm{p}<0.05$ (as determined by two-tailed homoscedastic Student's $t$-test).

vector at 1-3 days of age $\left(4 \times 10^{13}\right.$ vector particles $/ \mathrm{kg}$ body weight). AAV2/9-G6Pase has demonstrated good hepatorenal correction in G6pase $(-/-)$ mice and was thus used in the dogs [18]. Puppies were weighed at least weekly for the first 7 weeks of life and weaned at 8 weeks of age (Figs. 4A, B). Adult weights were obtained after 20 months of life (Fig. 4C). For a more detailed report of puppy care, refer to DeMaster et al. [14]. Numbers of animals lost over time were due to death of affected puppies, adoption of unaffected littermates or missed data entry (Table S1).

\subsection{Murine GH-related quantification assays}

Total RNA was extracted from mouse tissues using RNeasy Mini Kit (Qiagen, Valencia, CA). Three $\mu \mathrm{g}$ of total RNA was reverse transcribed with 300 units of M-MLV reverse transcriptase (Life Technologies, Inc.,

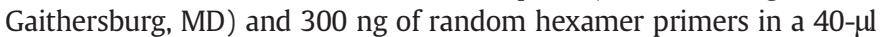
reaction. mRNA levels were quantified with an ABI 7300 Real time PCR system, as described previously [21,22]. For measurements of mature mRNA, all primer pairs spanned introns; amplicon lengths ranged from 90 to $150 \mathrm{bp}$. Thermal cycling conditions were $10 \mathrm{~min}$ at $95{ }^{\circ} \mathrm{C}$ followed by $35-40$ cycles for $15 \mathrm{~s}$ at $95^{\circ} \mathrm{C}$ and $1 \mathrm{~min} 57^{\circ} \mathrm{C}$; SYBR green incorporation into a single peak was monitored using a dissociation curve. Expression levels were normalized against the levels of acidic riboprotein, a housekeeping gene that shows little change during cellular growth or differentiation [23]. The levels of mRNA were quantified using the comparative threshold cycle $\left(C_{T}\right)$ method [24]. Table 1 shows the oligonucleotide primer pairs, all of which encode mouse genes, and $\mathrm{C}_{\mathrm{T}}$ values obtained in mouse liver.

\subsection{Serum or plasma GH and IGF 1 concentrations}

The ELISA for murine plasma GH was performed according to the manufacturer's instructions (KRC5311, Life Technologies, Grand Island, NY) or (ALPCO, Salem, NH) from mice between 10 and 13 days of age. The ELISA for murine plasma IGF 1 was performed according to the 

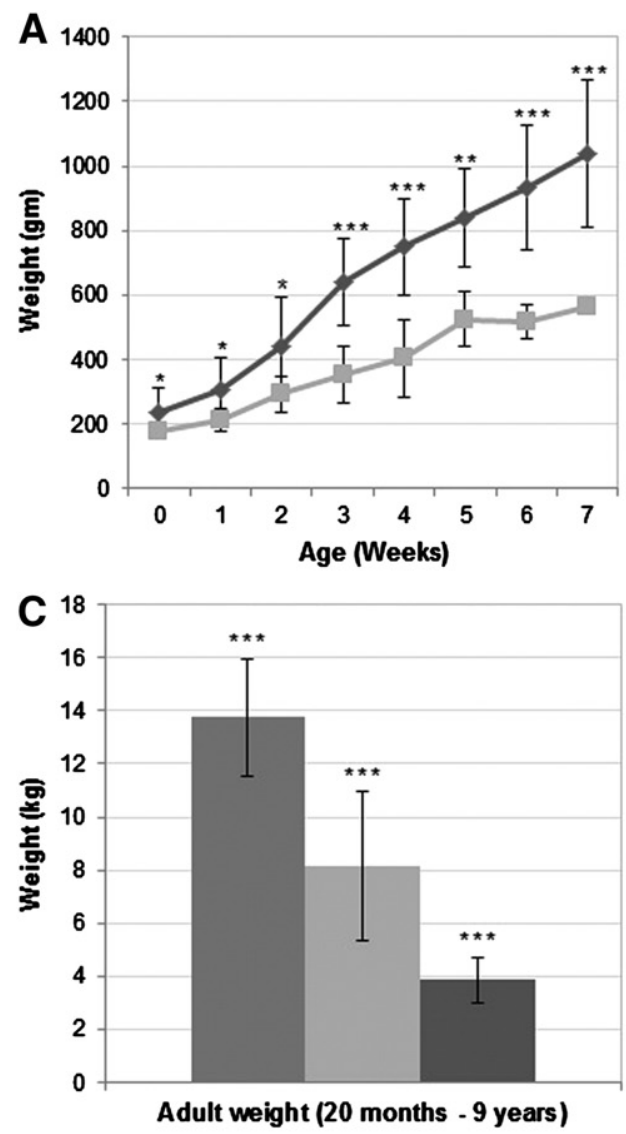
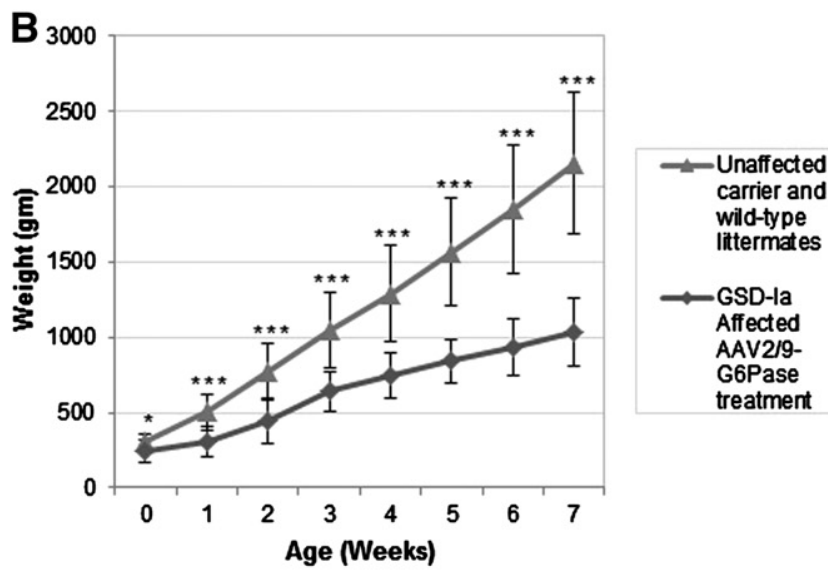
wild-type littermates G6Pase treatment - GSD-la Affected dietary therapy

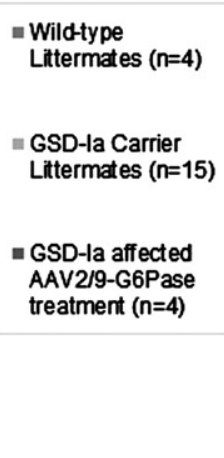

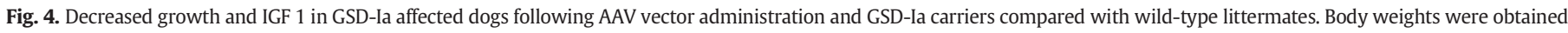

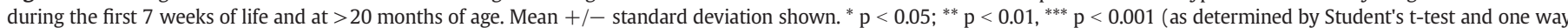

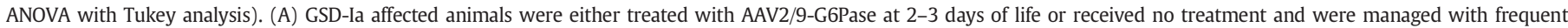

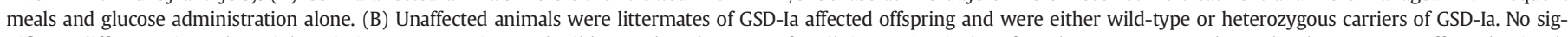

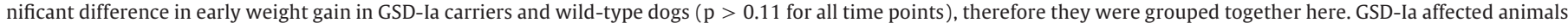

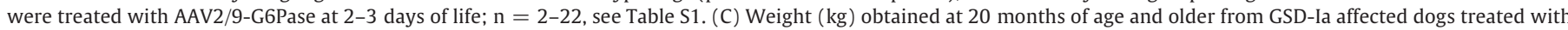

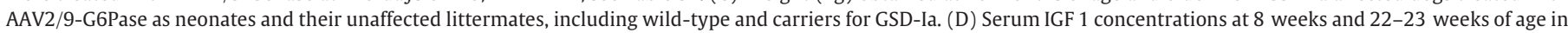

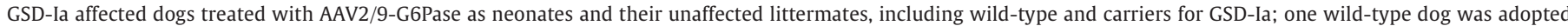
prior to 20 weeks accounting for $n=1$ at 22-23 weeks.

manufacturer's directions, except the IGF 1 standard was diluted to $10 \mathrm{ng} / \mathrm{ml}$ rather than $2 \mathrm{ng} / \mathrm{ml}$ (EA-2204, Signosis, Sunnyvale, CA). Canine serum IGF 1 concentrations were measured by a reference laboratory (Diagnostic Center for Population \& Animal Health, Michigan State University, Lansing, MI) from blood taken at 8 weeks of age and between 22 and 23 weeks of age for two different litters (Fig. 4D). Blood was taken at 33 months of life from littermates, one GSD-Ia affected AAV2/9-G6Pase vector-treated female and two GSD-Ia carrier males remaining in the study. Animals were not fasted prior to blood collection.

\subsection{Western blotting}

Antibodies against mouse fatty acid synthase (FASN) (ab3844, Abcam, Cambridge, MA), c-Fos (ab7963, Abcam), signal transducer and activator of transcription (STAT5) (phospho Y694) (ab32364,

Table 1

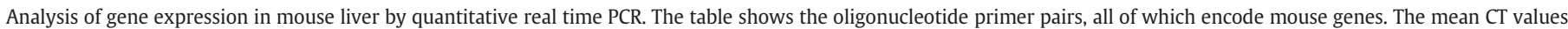
shown in the table were obtained from liver samples of wild-type mice.

\begin{tabular}{|c|c|c|c|}
\hline mGene & Accession \# & $\begin{array}{l}\text { Primers } \\
\text { (top forward, bottom reverse) }\end{array}$ & Mean CT values \\
\hline PRLR-L & NM_001034111 & $\begin{array}{l}\text { 5' CCT GCA TCT TTC CAC CAG TTC 3' } \\
5^{\prime} \text { GCA CTC AGC AGT TCT TCA GAC TTG 3' }\end{array}$ & 24 \\
\hline GHR-L & NM_017094 & $\begin{array}{l}\text { 5' CCA GTT TCC ATG GTT CTT AAT TAT TAT 3' } \\
5^{\prime} \text { ATC TTA ATC CTT TGC TGC TTT GAA AA 3' }\end{array}$ & 22 \\
\hline Insulin receptor & NM_010568 & $\begin{array}{l}\text { 5' GCA GTG TGG CAG CCT ACG T3' } \\
\text { 5' CAG GGC CAA CGA TGT CAT CT 3' }\end{array}$ & 23 \\
\hline IGF 1 & NM_010512 & $\begin{array}{l}\text { 5' CCA CAC TGA CAT GCC CAA GAC 3' } \\
5^{\prime} \text { TGC AGC TTC GTT TTC TTG TTT G } 3^{\prime}\end{array}$ & 21 \\
\hline IGF 2 & NM_010514 & $\begin{array}{l}5^{\prime} \text { TGT CTA CCT CTC AGG CCG TAC TT 3' } \\
5^{\prime} \text { CCA GGT GTC ATA TTG GAA GAA CTT G 3' }\end{array}$ & 17 \\
\hline Acidic riboprotein - PO & NM_007475 & $\begin{array}{l}\text { 5' CCC TGA AGT GCT CGA CAT CA 3' } \\
5^{\prime} \text { GCG GAC ACC CTC CAG AAA GC 3' }\end{array}$ & 21 \\
\hline
\end{tabular}


Abcam), and $\beta$-actin (ab20272, Abcam) were used for Western blotting analysis (Figs. 2A, B). Western blot was performed in the same manner described in Sun et al. [25].

\subsection{Canine body weight analysis}

Body weights were extracted from the medical records retrospectively over the course of several years for GSD-la affected dogs treated with AAV2/9-G6Pase $(\mathrm{n}=8)$ 1-3 days after birth, GSD-Ia affected dogs treated only with dietary supplementation from birth $(n=7)$ and unaffected littermates $(n=22)$ for the first 7 weeks of life (Figs. 4A, B, Table S1). Adult (20 months-9 years of age) body weights were obtained from medical records of GSD-Ia AAV2/9-G6Pase vector-treated dogs currently in the study ( $\mathrm{n}=4,3$ males, 1 female), dogs in the GSD-la carrier breeding colony ( $\mathrm{n}=10,4$ males, 6 females) or as reported by owners from those unaffected dogs that were adopted out of the study, containing both carrier ( $\mathrm{n}=5,1$ male, 4 females) and wild-type dogs ( $\mathrm{n}=4,4$ males) (Fig. 4C). Body condition score (BCS) was determined based on a 9-point scale by Duke University animal care staff or the owners based on the "Body Condition System" chart by Nestlé Purina (St. Louis, Missouri) [26].

\subsection{Mouse limb staining}

12-Day-old mouse tissues were collected from whole G6pase $(-/-)$ and wild-type mice that were frozen and stored in $-80^{\circ} \mathrm{C}$, mice were then thawed, imaged by high resolution radiography (methods below) and then skin was removed from limbs and tail. Limbs were then stained whole using Alcian blue for cartilage and Alizarin red for bone according to the methods found in Yamazaki et al. [27] (Fig. 5).

\subsection{Murine radiographic measurements and analysis}

Radiographs of mice were taken of euthanized G6pase (-/-) and wild-type mice at 12 days or at 6 months of life using a model MX20 Faxitron machine (Faxitron X-ray Corporation, Wheeling, IL) and processed with Dalsa specimen radiography system version 1.0 (Dalsa Life Sciences, Tucson, AZ). Mice were imaged in right and left lateral, ventrodorsal and dorsoventral positions to obtain high resolution images of the axial and appendicular skeleton (Fig. 6). All radiographs were measured independently by two trained graders measuring bone lengths using Image J (Wayne Rasband, National Institutes of Health, USA) (Fig. S1).

\subsection{Canine radiographic measurements and analysis}

Radiographs were taken of dogs with an InnoVet select E7242x $\mathrm{X}$-ray machine (Summit Industry, Chicago, IL) and processed using an IDEXX-CR 1417 digital imaging system (IDEXX Laboratories, Inc., Westbrooke, ME). Bone dimensions were measured from radiographs taken using right and left lateral, ventrodorsal and dorsoventral positioning of animals.

Radiographs of 3-month-old male dogs under brief physical restraint were taken of the front legs due to intermittent forelimb lameness noted in a male GSD-Ia affected dog treated with AAV2/9-G6Pase on the first day of life, radiographs of a male wild-type littermate were obtained at the same time for comparison. These radiographs were measured retrospectively; several measurements were not obtainable due to variation in procedure and poor positioning. Radiographs of a 3-month-old female GSD-la carrier in a different litter were obtained under sedation for comparison (Fig. 7A, Tables S2, S3).

Photographs were taken of a 34-month-old GSD-la affected female dog who had been treated with AAV2/9-G6Pase at 1 day of age and retreated with AAV2/8-G6Pase at 15 months of age and her male

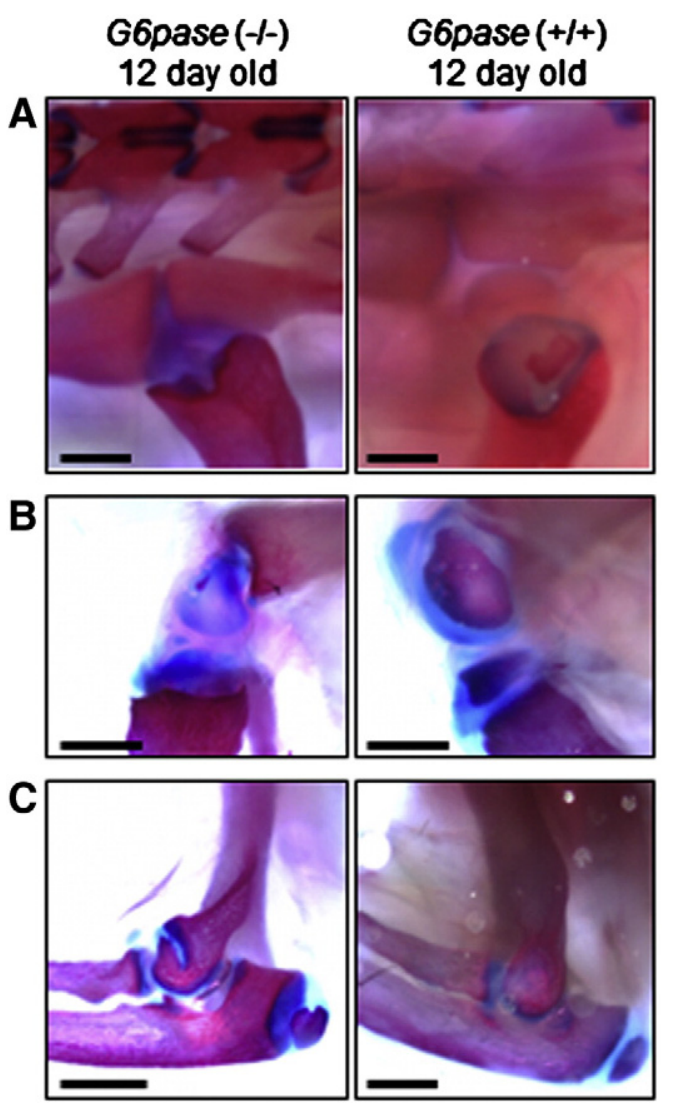

Fig. 5. Dyschondrogenesis of G6pase (-/-) mice at 12 days of age. Alcian Blue/Alizarin Red whole limb staining of 12-day old glucose treated G6pase $(-/-)$ mice $(\mathrm{n}=3)$ and G6pase $(+/+)$ mice $(n=3)$. Images representative of all animals analyzed. (A) Hip shows delay in secondary ossification in G6pase $(-/-)$ mice. (B) Knee of G6pase $(-/-)$ mice demonstrates severe delay in secondary ossification and malformation of distal femur and proximal tibia. (C) Elbow of G6pase $(-/-)$ mouse demonstrates delay in ossification and deformity of proximal radius and ulna. Cartilage stains blue and bone stains red/pink. Scale bar $=1 \mathrm{~mm}$. Craniad to the left of the images and proximal at the top.

GSD-la heterozygous littermate, who had also received AAV2/ 9-G6Pase at 1 day of age (Fig. 7B, Table S4).

Radiographs were performed under sedation on the same GSD-Ia affected female dog above at 37 months of age and a different male GSD-Ia heterozygous littermate, who had also received AAV2/ 9-G6Pase at 1 day of age (Figs. 7C-E, Tables S2, S4). All radiographs were measured independently by two trained graders measuring calibrated bone lengths and widths using ClearCanvas Workstation 2.0 (Toronto, ON, Canada). Graders varied from a $0.02 \mathrm{~mm}$ to $5.91 \mathrm{~mm}$ difference in individual bone measurements, with a mean $0.83 \pm$ $1.01 \mathrm{~mm}$ difference. Measurements were averaged between graders and included in Supplemental Tables 3 and 4.

\subsection{Statistical analysis}

A two-tailed homoscedastic Student's t-test was used to determine significant differences in measurements between G6pase (-/-) mice and wild-type mice. A one-tailed heteroscedastic Student's $t$-test was used to compare between weights at each time point for the GSD-la canine growth curve (Figs. 4A, B). Kruskal-Wallis Test was used to determine significance of mouse radiographic bone lengths (Fig. S1). One way between subjects ANOVA with Tukey analysis was used to compare IGF 1 values and adult body weights between wild-type, GSD-Ia carriers and GSD-la affected dogs treated with AAV2/9-G6Pase (Figs. 4C, D). P values less than 0.05 were considered significant. 


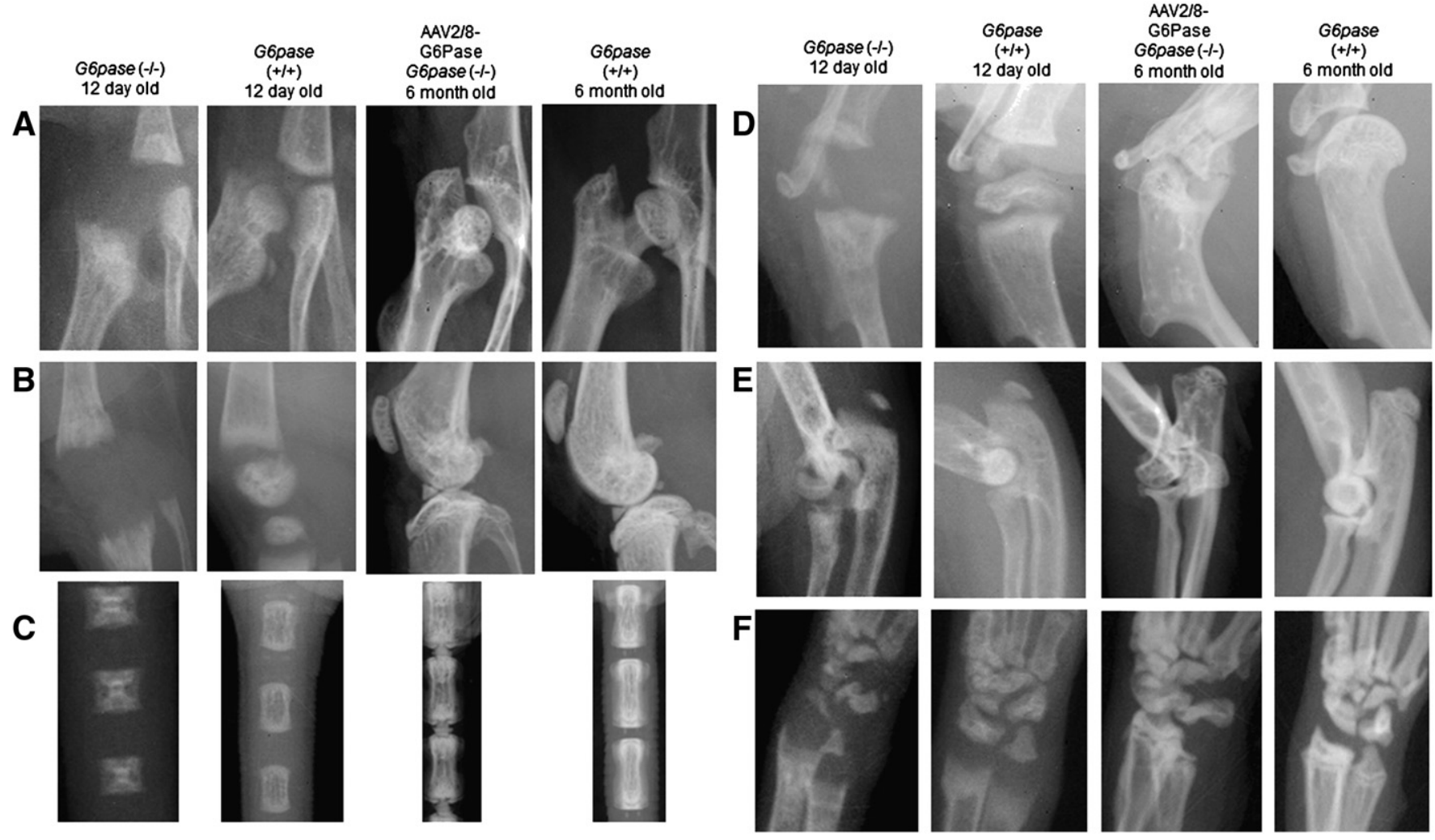

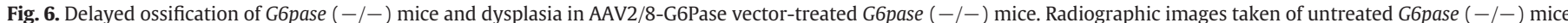

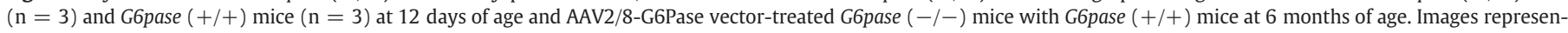

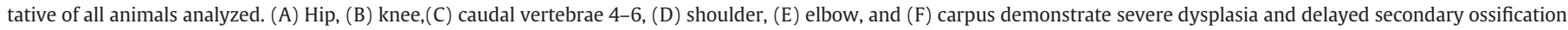
in G6pase (-/-) mice.

\section{Results}

\subsection{Murine GSD-Ia hepatic GH signaling and IGF production}

As shown in Fig. 1A, randomly sampled plasma GH concentrations in G6pase (-/-) mice not treated with glucose injections (UT) were comparable to those in wild-type controls. However, GH concentrations were decreased in glucose-treated G6pase $(-/-)$ mice (Fig. 1A; GT) indicating either suppression from glucose therapy or a general GH deficiency. Plasma GH concentrations in young, glucose-treated, unaffected mice varied from $<1$ to $41 \mathrm{ng} / \mathrm{ml}(11 \pm$ $16 \mathrm{ng} / \mathrm{ml} ; \mathrm{n}=6$; not shown), indicating that this type of glucose treatment may suppress $\mathrm{GH}$ as expected in some mice, but not all. These findings suggest that regulation of pituitary GH secretion is largely preserved in GSD-Ia. On the other hand, plasma IGF 1 levels were reduced in neonatal G6pase (-/-) mice (Fig. 1B), suggesting that GH induction of IGF 1 expression may be attenuated. Support for this hypothesis was provided by studies of basal levels of GHR-L receptor, PRLR-L receptor, and IGF 1 mRNAs, which reduced by $55-70 \%(\mathrm{p}<0.01)$ in untreated neonatal G6pase $(-/-)$ mice. In contrast, hepatic expression of IGF 2 mRNA was normal (Fig. 1C).

Moreover, hepatic levels of phosphorylated STAT5 (phospho Y694) and c-Fos were reduced in both glucose-treated and untreated G6pase (-/-) mice compared with G6pase $(+/+)$ mice, consistent with decreased hepatic GH signaling [28] (Figs. 2A, B). Accordingly, the administration of $\mathrm{GH}$ and glucose caused little or no increase in hepatic IGF 1 mRNA in GT G6pase $(-/-)$ mice compared with G6pase (+/+) mice (Fig. 2D), and GH-stimulated weight gain was blunted in comparison to that observed in wild-type mice: GH treatment for 7 days increased body weight by $38 \%(\mathrm{p}<0.02)$ in unaffected $[$ G6pase $(+/+)$ and $(+/-)]$ controls but had no significant effect in G6pase (-/-) mice (Fig. 2C).
3.2. AAV2/8-G6Pase administration to G6pase (-/-) mice rescues adult growth, but not plasma IGF 1

The GSD-Ia liver features massive accumulation of lipids as well as glycogen [29]. Accordingly, hepatic FASN was increased in G6pase $(-/-)$ mice (Figs. 2A-B) [30]. AAV2/8-G6Pase administration increased hepatic G6Pase activity, reduced glycogen accumulation to the levels observed in wild-type mice, and prevented fasting hypoglycemia [16], however, the weight gain of vector-treated G6pase (-/-) mice was significantly decreased at 1 month in comparison with wild-type controls (Fig. 3A). Body weight normalized by 2-3 months and plasma IGF 1 in the G6pase $(-/-)$ mice was not significantly reduced at 2 months of age, indicating an initial improvement from AAV2/8-G6Pase therapy (Fig. 3B). However, G6pase (-/-) plasma IGF 1 was significantly decreased at 4 and 6 months of age while body weight trended lower in comparison with wild-type mice at 6 months of age without reaching statistical significance (Fig. 3A).

\subsection{AAV2/9-G6Pase administration to GSD-Ia affected dogs partially rescues growth compared to dietary therapy alone}

GSD-la affected dogs receiving only dietary treatment were 70\% $(214 \pm 34 \mathrm{~g}, \mathrm{n}=6)$ of the weight of AAV2/9-G6Pase vector-treated dogs (307 $\pm 100 \mathrm{~g}, \mathrm{n}=8, \mathrm{p}=0.02$ ) at 1 week of age and only $54 \%$ ( $565 \pm 15 \mathrm{~g}, \mathrm{n}=2$ ) of weight of AAV2/9-G6Pase vector-treated dogs $(1038 \pm 226 \mathrm{~g}, \mathrm{n}=7, \mathrm{p}<0.001)$ at 7 weeks of age (Fig. 4A). Neonatal AAV2/9-G6Pase therapy increased growth rate of GSD-la dogs compared to dietary therapy alone, but growth curves of these animals did not parallel those of unaffected littermates at any time in the 7 week study period (Fig. 4B). For example, AAV2/9-G6Pase treated dogs were $61 \%$ of unaffected littermates' weight $(502 \pm 118 \mathrm{~g}, \mathrm{n}=22$, $\mathrm{p}=0.0002$ ) at 1 week of age and $48 \%$ the weight of unaffected 

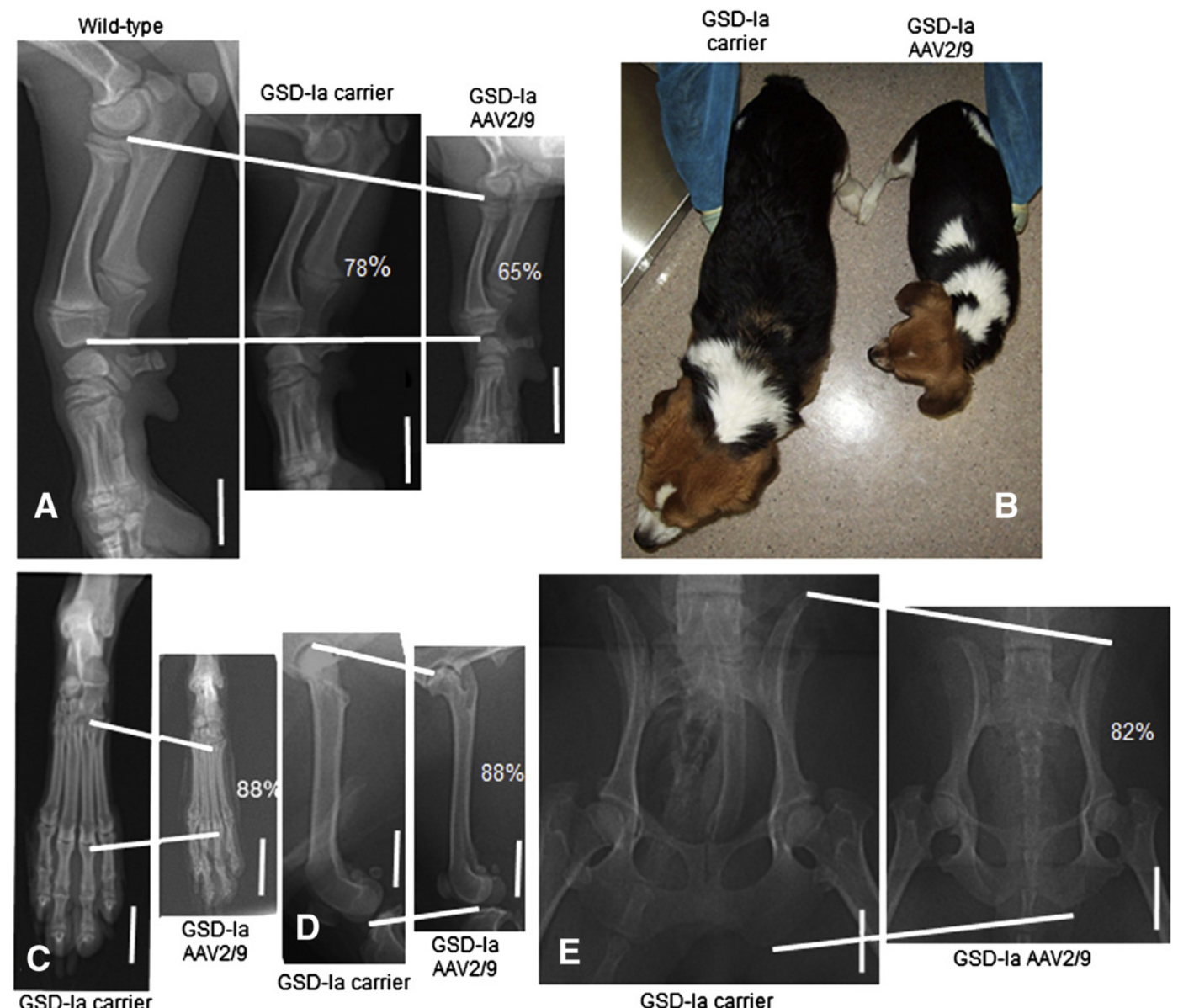

GSD-la carrier

Fig. 7. Decreased bone dimensions in GSD-Ia affected dogs treated with AAV2/9-G6Pase compared with unaffected littermates. (A) Mediolateral radiographic view taken of forelimb at 3 months of age from a GSD-Ia male affected dog (right) treated with AAV2/9-G6Pase, his wild-type male littermate (left), and a female GSD-la carrier from a different litter (middle). Note a 65\% difference in radius length of the GSD-Ia affected dog treated with AAV2/9-G6Pase and wild-type littermate, versus a 78\% difference between GSD-Ia carrier and wild-type (see Table S3). Dogs weighed $3.9 \mathrm{~kg}$ (A), $3.2 \mathrm{~kg}$ (B) and $1.8 \mathrm{~kg}$ (C) at time radiographs were taken. White marker represents $15 \mathrm{~mm}$. (B) Photograph of 34-month-old female GSD-Ia AAV2/9-G6Pase vector-treated dog (right) and male GSD-Ia carrier littermate (left) who weighed $8.2 \mathrm{~kg}$ at the time the picture was taken. (C-E) Radiographic analysis performed at 37 months of age of same female GSD-la AAV2/9-G6Pase treated dog (right) and a different male GSD-la carrier littermate (left). Dogs weighed $3.8 \mathrm{~kg}$ and $8.6 \mathrm{~kg}$, respectively, at time of radiographs. White marker represents $15 \mathrm{~mm}$. (C) Plantardorsal radiographic view of the right rear foot, metatarsals and proximal phalangeal bones of a female GSD-la AAV-G6Pase treated dog were approximately 88 and 87\%, respectively, the length of her male GSD-la carrier littermate. (D) Lateral radiographic view of the femur of a female GSD-Ia AAV-G6Pase treated dog was approximately 88\% the length of those of her male GSD-la carrier littermate, but 70\% the width. (E) Ventrodorsal radiographic view of the pelvis of a female GSD-la AAV-G6Pase treated dog was approximately $82 \%$ and $76 \%$ the length and width, respectively, of the pelvis of her male GSD-la carrier littermate (see Table S4).

littermates $\left(2153 \pm 472 \mathrm{~g}, \mathrm{n}=22, \mathrm{p}=2.18 \times 10^{-8}\right)$ at 7 weeks of age. Bodyweights of wild-type and GSD-la heterozygous carriers were not significantly different $(\mathrm{p}>0.11)$ during the 7 weeks, and were therefore grouped together as an unaffected littermate group (Fig. 4B). There was, however, some minor divergence of growth curves beginning at 5 weeks of age between wild-type and GSD-Ia carriers (not shown).

\subsection{Adult AAV2/9-G6Pase vector-treated GSD-Ia affected dogs and GSD-Ia carriers are smaller than adult wild-type littermates}

At 34 months of age, a GSD-Ia affected AAV2/9-G6Pase vectortreated female dog was grossly smaller in size and stature (Fig. 7B) and weighed $46 \%$ (3.8 $\mathrm{kg}$ ) of the weight of her heterozygous GSD-Ia carrier male littermate $(8.2 \mathrm{~kg})$. Among adult dogs (20 months9 years of age), AAV2/9-G6Pase treated dogs $(n=4)$ averaged $3.9 \pm 0.8 \mathrm{~kg}$ body weight, while their wild-type littermates $(\mathrm{n}=4)$ averaged $13.8 \pm 2.2 \mathrm{~kg}$ body weight, whereas, GSD-Ia carriers averaged $8.1 \pm 2.8 \mathrm{~kg}$ body weight $(\mathrm{n}=15)$ (Fig. 4C). BCS was not statistically significant among all dogs based on a 9-point scale, ranging from 3.5 to 6 (not shown).
3.5. AAV2/9-G6Pase treatment does not rescue serum IGF 1 concentrations in GSD-Ia affected dogs and GSD-Ia carrier dogs have reduced serum IGF 1 compared to wild-type littermates

Serum IGF 1 was $1.7 \pm 0.6 \mathrm{nmol} / \mathrm{L}$ in AAV2/9-G6Pase treated GSD-la dogs ( $\mathrm{n}=3,2$ males, 1 female), $15.3 \pm 5.2 \mathrm{nmol} / \mathrm{L}$ in GSD-la carrier dogs ( $\mathrm{n}=4,2$ males, 2 females) in comparison with $43.5 \pm 7.8 \mathrm{nmol} / \mathrm{L}$ in their male wild-type littermates $(\mathrm{n}=2$, $\mathrm{p}<0.001$ ) at 8 weeks of age (Fig. 4D). At 22-23 weeks of age, serum IGF 1 was $2.7 \pm 2.1 \mathrm{nmol} / \mathrm{L}$ in the same GSD-Ia dogs $(\mathrm{n}=3)$; $14.8 \pm 7.0 \mathrm{nmol} / \mathrm{L}$ in the same GSD-Ia carrier $\operatorname{dogs}(\mathrm{n}=4 \mathrm{p}=0.018)$ and $27 \mathrm{nmol} / \mathrm{L}$ in a wild-type littermate. At 33 months of age, serum IGF 1 levels were $1.0 \mathrm{nmol} / \mathrm{L}$ in a female AAV2/9-G6Pase treated GSD-Ia dog $(\mathrm{n}=1)$ and $10.5 \pm 2.1 \mathrm{nmol} / \mathrm{L}$ in her carrier male littermates $(\mathrm{n}=2)$ (Table S2).

Normal canine IGF 1 reference range from the reference laboratory was 4-95 nmol/L (31-725 ng/ml), but spans a wide variety of ages and breeds. Based on data from Greer et al., normal IGF 1 concentrations for dogs of the size and age of the dogs in the current study should be between 20 and $320 \mathrm{ng} / \mathrm{ml} \mathrm{(3-42} \mathrm{nmol/L)} \mathrm{[31];} \mathrm{whereas,}$ data from Jaillardon et al. indicate IGF 1 for adult dogs $<15 \mathrm{~kg}$ $(\mathrm{n}=177)$ ranges from 21 to $433 \mathrm{ng} / \mathrm{ml}(3-57 \mathrm{nmol} / \mathrm{L})$ with a mean 
of $117 \mathrm{ng} / \mathrm{ml}(15 \mathrm{nmol} / \mathrm{L})$, and no significant difference in IGF 1 with age [32].

3.6. Delayed ossification of G6pase (-/-) mice and dysplasia and decreased bone dimensions in AAV2/8-G6Pase vector-treated

G6pase (-/-) mice

Alcian Blue and Alizarin Red staining of whole limbs in 12-day-old G6pase (-/-) mice compared to wild-type mice demonstrated delay in ossification of the femoral head, delay in development of secondary centers of ossification in the physes of the distal femur and proximal tibia, and dysplasia of the elbow, with delayed physeal closure and abnormal angulation of the distal humerus resulting in incongruence of the distal humerus relative to the proximal radius and ulna. Abnormal metaphyseal morphology of the proximal radius was also noted (Fig. 5).

Hip radiographs of four groups of mice (Fig. 6A) confirmed delay in ossification of the femoral head in 12-day-old G6pase (-/-) mice, and dysplasia of the hip and exaggerated development of the third trochanter in 6-month old G6pase (-/-) AAV2/8-G6Pase vector-treated mice. Knee radiographs (Fig. 6B) demonstrated thickening and irregularity of the metaphyseal growth plate of the proximal tibia and distal femur, with delay in development of secondary centers of ossification in 12-day-old G6pase (-/-) mice compared to unaffected controls. In 6-month-old mice, there was irregularity and flattening of the femoral condyles, and bowing of the fibulae of G6pase (-/-) AAV2/8-G6Pase vector-treated mice compared to unaffected. In caudal vertebrae 4-6 (Fig. 6C), besides shortening of the vertebrae in both affected groups, there was premature mineralization of the caudal intervertebral disks in the tail in 6-month-old G6pase (-/-) AAV2/8-G6Pase vector-treated mice. This abnormality was observed only in the proximal $1 / 3$ of the tail. In the shoulder (Fig. 6D), elbow (Fig. 6E) and carpus/wrist (Fig. 6F), there was severe dysplasia in G6pase (-/-) 12-day-old mice, with widening and irregularity of the metaphyseal growth plates and impaired development of secondary centers of ossification, with premature severe arthritis evident in 6-month-old G6pase (-/-) AAV2/8-G6Pase vector-treated mice compared to unaffected mice of similar age. Enthesiopathies were also evident, particularly at the deltoid tuberosity of the proximal humerus, where widening and lengthening were noted in 6-month-old G6pase (-/-) AAV2/8-G6Pase vector-treated mice compared to unaffected mice of similar age. In hips (Fig. 6A), knees (Fig. 6B) and elbows (Fig. 6E) of 6-month-old G6pase (-/-) AAV2/8-G6Pase vector-treated mice, the trabecular bone pattern of the proximal femur, patella, distal femur, proximal tibia, distal humerus and olecranon was enhanced, and there was increased cortico-medullary contrast in the proximal femur and patella, suggestive of some degree of osteoporosis.

Long bones of the extremities were uniformly shorter in G6pase $(-/-)$ mice compared with wild-type at both 12 days and 6 months of life (Fig. S1A). The long bones in weight bearing digits (the third metatarsals and phalanges) showed a significant difference between G6pase (-/-) mice and unaffected mice at both 12 days and 6 months of age, whereas the bones in non-weight bearing digits were not significantly different between GSD-la in 6-month-old mice, despite the difference between both groups at 12 days of age (Fig. S1B). The heads and third cervical vertebrae of mature G6pase $(-/-)$ mice are smaller than the unaffected mice, but other vertebrae, ilium and ischium are not significantly different in 6-month-old vector treated mice (Fig. S1C).

3.7. Bone dimensions were decreased in AAV2/9-G6Pase treated GSD-Ia affected dog and GSD-Ia carrier compared to wild-type

At 3 months of age, forelimb long bone dimensions of an AAV2/ 9-G6Pase treated GSD-Ia affected male dog were smaller than those of a male wild-type littermate, while long bone dimensions of a female
GSD-la carrier were also smaller than that of the male wild-type. Long bone dimensions of the AAV2/9-G6Pase treated GSD-Ia affected male dog at this age were also smaller than the female GSD-Ia carrier of the same age (Fig. 7A, Table S3). The wild-type dog weighed $3.9 \mathrm{~kg}$, the GSD-la carrier weighed $3.2 \mathrm{~kg}$, and the GSD-Ia AAV2/9-G6Pase dog weighed $1.8 \mathrm{~kg}$ at time radiographs were taken.

At 37 months of age, long bone dimensions, pelvic dimensions and vertebral dimensions of an AAV2/9-G6Pase treated GSD-Ia affected female dog were smaller than those of a GSD-la carrier male littermate (Figs. 7C-E, Table S4). Dogs weighed $3.8 \mathrm{~kg}$ and $8.6 \mathrm{~kg}$, respectively, at time of radiographs. Radiographs of wild-type animals at this age were not available for comparisons because they had left the study.

\section{Discussion}

\subsection{Proposed pathogenesis of growth failure in GSD-Ia}

The pathogenesis of growth failure in Glycogen Storage Disease is complex; contributing factors may include restricted diet, acidosis, hypercortisolemia (from recurrent hypoglycemia [5]), and hepatic and renal insufficiency. Here we explored the role of hepatic GH signaling and IGF production in GSD-la using a G6Pase deficient mouse model. We showed that hepatic IGF 1 mRNA levels and plasma IGF 1 concentrations are low despite normal randomly sampled GH concentrations, and body weight gain fails to increase in response to exogenous GH. These observations suggest that GSD-Ia is associated with hepatic GH resistance. The low levels of phosphoSTAT5 and c-Fos in liver and the failure of hepatic IGF 1 mRNA to rise in response to $\mathrm{GH}$ treatment provides strong support for this hypothesis.

The GH resistance of mice with G6Pase deficiency results, at least in part, from a reduction in liver GH receptor expression. In theory, the decrease in GH receptor expression might be caused by hepatic inflammation induced by excess glycogen and/or lipid accumulation or might reflect a defect in $\mathrm{GH}$ receptor transcription related to dysfunctional intracellular glucose metabolism. G6pase $(-/-)$ mice also had reductions in hepatic PRL receptors which activate STAT5 in rat liver, albeit with considerably lower potency than GH [33]. Thus the reduction in PRL receptor expression may contribute slightly to the fall in phospho STAT5 in livers of G6Pase deficient mice. However, PRL, in contrast to GH, does not induce hepatic IGF 1 production $[34,35]$.

\subsection{Role of IGF 1 on bone development}

We noted delayed ossification in G6pase (-/-) mice at 12 days of age likely due to the decrease in IGF 1 . IGF 1 increases cell proliferation and protein synthesis and can stimulate long bone growth [36], probably through its effects on chondrocyte proliferation and hypertrophy [37-39]. However, IGF 1 action at the level of the chondrocyte is regulated by a complex series of paracrine and autocrine feedback loops [38], such that the impact of low serum IGF 1 on chondrocyte proliferation in the current study is unknown. Depletion of IGF 1 and a key serum stabilizer of serum IGF 1 leads to growth retardation in several mouse studies, but hepatic-specific depletion of IGF 1 alone does not impair growth [40]. However, the marked increase in growth velocity in patients after liver transplantation suggests that there may be at least some endocrine effect of normalized serum IGF 1 on recovery of growth [11-13]. As far as we know, there are no reports of IGF 1 concentrations before and after liver transplantation in GSD-Ia patients.

In contrast to IGF 1 , hepatic IGF 2 mRNA levels in the G6pase (-/-) mice were normal; this is not surprising, given the variable reductions in serum IGF 2 in patients with GH deficiency and the limited (or lack of) effect of GH treatment on circulating IGF 2 levels in children and adults [41-43]. 
4.3. AAV-G6Pase therapy fails to fully correct growth failure in GSD-Ia canine and murine models

Partial reconstitution of hepatic G6Pase through AAV vector transduction promoted weight gain in G6pase $(-/-)$ mice after a delay of 2-6 weeks; interestingly, plasma IGF 1 concentrations declined after 2 months of age, suggesting that $\mathrm{GH}$ resistance persists despite catch-up weight gain. It is of note that the initial delay in weight gain in GSD-la mice occurs during the period prior to and during expected sexual maturation; this may explain in part the delayed puberty and late catch-up growth observed in many children and teenagers with Glycogen Storage Disease. We also found that administration of AAV2 9-G6Pase to GSD-Ia dogs within 3 days of birth partially rescues growth compared to dietary therapy, as assessed by bodyweight, but fails to rescue serum IGF 1 or bone dimensions. Our findings are consistent with clinical studies showing that height $\mathrm{z}$ score correlates positively with plasma IGF 1 concentrations and inversely with GH levels in children with various forms of Glycogen Storage Disease [5,44].

\subsection{Timing of AAV2/9-G6Pase administration relative to development}

The reasons for failure of AAV2/9-G6Pase treatment administered in the neonatal period (days 1-3 post-partum) to fully correct growth failure in dogs and mice are unknown and are likely multifactorial and complex. That normal weight gain can be achieved following administration of AAV-G6Pase therapy during infancy in mice, but not in dogs suggests differences in comparative development between dog and mouse may play a role. In the mouse, dog and human, the appearance of the proximal epiphysis of the humerus occurs at postpartum days 5-10, weeks $1-2$, and as early as gestational weeks 36-40, respectively [45], suggesting different absolute rates of skeletal development across species. This has been shown to occur in the nervous system across species [46], but similar cross-species modeling has not yet been applied to specific markers of hepatic or musculoskeletal development, which is likely to be more difficult given axial-appendicular and craniad-caudad developmental gradients. For example, we found that fewer structures in the caudal component of the axial skeleton demonstrated persistent shortening than in the craniad axial skeleton in AAV 2/8-G6Pase vector-treated mice (Fig. S1D) suggesting that timing of administration of treatment in GSD-Ia affected mice was appropriate to rescue growth in the caudad component of the axial skeleton, but was delayed relative to growth correction in the craniad axial skeleton.

\subsection{Heterozygous GSD-Ia carriers demonstrate growth deficiency}

Although canine carriers for GSD-Ia do not appear to exhibit overt clinical signs, they do demonstrate metabolic abnormalities and growth deficiencies. Weinstein et al. have demonstrated that there is about a 50\% decrease in hepatic G6Pase activity, increased hepatocellular glycogen and an increase in blood lactate after $12 \mathrm{~h}$ of fasting in GSD-la carrier animals compared with wild-type dogs [17]. We also demonstrated decreases in IGF 1 concentrations in carrier dogs in comparison to wild-type dogs (Fig. 4D) as well as decreases in adult body weight (Fig. 4C). However, to our knowledge, metabolic and growth abnormalities have not been demonstrated in carrier parents of affected GSD-Ia human patients.

\subsection{Summary}

Our findings indicate that growth failure and IGF 1 deficiency of GSD-la appears to result, at least in part, from hepatic resistance to $\mathrm{GH}$ action. As noted here, gene therapy of GSD-la affected dogs and mice can prolong survival, prevent fasting hypoglycemia, and reduce hepatic steatosis but fails to normalize bone growth and IGF 1 production $[14,16,17,47,48]$. It is possible that more effective gene therapy at an early time point would fully normalize hepatic G6Pase expression, reverse hepatic-based GH resistance, and normalize growth $[16,17,48]$. Until more effective gene vectors are developed, the therapy of growth failure in GSD-Ia remains focused on dietary measures. Given the state of $\mathrm{GH}$ resistance, $\mathrm{GH}$ treatment alone is not likely to be effective; the potential benefits of IGF 1 therapy remain to be explored. Our data will guide future studies in dog and mouse models to assess the endocrine, paracrine and autocrine effects of IGF 1 and growth hormone in GSD-la to develop the best method and timing of intervention to prevent growth failure in AAV-G6Pase treated GSD-Ia affected individuals.

\section{Conflict of interest statement}

The authors have no conflicts of interest to report with regard to this work.

Supplementary data to this article can be found online at http:// dx.doi.org/10.1016/j.ymgme.2013.03.018.

\section{Acknowledgments}

This work was funded in part by the Children's Fund for GSD Research, the Association for Glycogen Storage Disease, Alice and YT Chen Center for Pediatric Genetics and Genomics, For the Love of Christopher, and the Duke Children's Miracle Network. Dr. Little received support from NIAMS (K08AR059784). Drs. Freemark and Arumugam received support from the NICHD (HD24192), American Diabetes Association, and Duke Children's Miracle Network. We deeply appreciate the dedication shown by Duke Vivarium, when caring for the G6pase $(-/-)$ mice and GSD-la dog colony. Much appreciation is also due to Dr. Shannon Smith, Ms. Songtao Li, Mr. Andrew Bird, Mr. Dustin J. Landau, Ms. Hiruni Amarasekara, and Ms. Maggie Chu for technical assistance and the extremely dedicated dog feeding crew. A special thanks is extended to all those that adopted unaffected dogs out of the study and provided additional data, including Dr. Kyha Williams, Laura Jordan, Jeff Lee, Arnette Williams, the Bird Family, Kieran Hendricksen, Dr. Baodong Sun, Deborah King, Janet Steele, Krista Beck, Christian Marsini and Randy Amoako. The authors acknowledge the helpful comments of Drs. Farshid Guilak and Y.-T. Chen on this work, as well as Dr. Kent Refsal for his information regarding IGF 1 testing in dogs.

\section{References}

[1] D.D. Koeberl, P.S. Kishnani, D. Bali, Y.T. Chen, Emerging therapies for glycogen storage disease type I, Trends Endocrinol. Metab. 20 (2009) 252-258.

[2] D.A. Weinstein, J.I. Wolfsdorf, Effect of continuous glucose therapy with uncooked cornstarch on the long-term clinical course of type 1a glycogen storage disease, Eur. J. Pediatr. 161 (Suppl. 1) (2002) S35-S39.

[3] D. Melis, R. Pivonello, G. Parenti, R. Della Casa, M. Salerno, F. Balivo, P. Piccolo, C. Di Somma, A. Colao, G. Andria, The growth hormone-insulin-like growth factor axis in glycogen storage disease type 1: evidence of different growth patterns and insulin-like growth factor levels in patients with glycogen storage disease type $1 \mathrm{a}$ and 1b, J. Pediatr.-Us 156 (2010), (663-U198).

[4] J.P. Rake, G. Visser, P. Labrune, J.V. Leonard, K. Ullrich, G.P. Smit, Glycogen storage disease type I: diagnosis, management, clinical course and outcome. Results of the European Study on Glycogen Storage Disease Type I (ESGSD I), Eur. J. Pediatr. 161 (Suppl. 1) (2002) S20-S34.

[5] H.R. Mundy, P.C. Hindmarsh, D.R. Matthews, J.V. Leonard, P.J. Lee, The regulation of growth in glycogen storage disease type 1 . Clin. Endocrinol. 58 (2003) 332-339.

[6] B. Schwahn, F. Rauch, U. Wendel, E. Schonau, Low bone mass in glycogen storage disease type 1 is associated with reduced muscle force and poor metabolic control, J. Pediatr. 141 (2002) 350-356.

[7] S. Dagdelen, A. Atmaca, A. Alikasifoglu, T. Erbas, Pituitary hypoplasia and growth hormone deficiency in a woman with glycogen storage disease type la: a case report, J. Med. Case Rep. 2 (2008) 210.

[8] J.I. Wolfsdorf, C.R. Rudlin, J.F. Crigler Jr., Physical growth and development of children with type 1 glycogen-storage disease: comparison of the effects of long-term use of dextrose and uncooked cornstarch, Am. J. Clin. Nutr. 52 (1990) 1051-1057.

[9] R.A. Noto, V. Vijayaraghavan, A. Timoshin, D. Sansobrino, Improved growth with growth hormone therapy in a child with glycogen storage disease Ib, Acta Paediatr. 92 (2003) 977-979.

[10] J.M. Nuoffer, P.E. Mullis, U.N. Wiesmann, Treatment with low-dose diazoxide in two growth-retarded prepubertal girls with glycogen storage disease type Ia resulted in catch-up growth, J. Inherit. Metab. Dis. 20 (1997) 790-798. 
[11] L. Faivre, D. Houssin, J. Valayer, J. Brouard, M. Hadchouel, O. Bernard, Long-term outcome of liver transplantation in patients with glycogen storage disease type Ia, J. Inherit. Metab. Dis. 22 (1999) 723-732.

[12] D. Matern, T.E. Starzl, W. Arnaout, J. Barnard, J.S. Bynon, A. Dhawan, J. Emond, E.B. Haagsma, G. Hug, A. Lachaux, G.P. Smit, Y.T. Chen, Liver transplantation for glycogen storage disease types I, III, and IV, Eur. J. Pediatr. 158 (Suppl. 2) (1999) S43-S48.

[13] S.G. Iyer, C.L. Chen, C.C. Wang, S.H. Wang, A.M. Concejero, Y.W. Liu, C.H. Yang, C.C. Yong, B. Jawan, Y.F. Cheng, H.L. Eng, Long-term results of living donor liver transplantation for glycogen storage disorders in children, Liver Transplant. 13 (2007) 848-852.

[14] A. Demaster, X.Y. Luo, S. Curtis, K.D. Williams, D.J. Landau, E.J. Drake, D.M. Kozink, A. Bird, B. Crane, F. Sun, C.R. Pinto, T.T. Brown, A.R. Kemper, D.D. Koeberl, Long-term efficacy following readministration of an adeno-associated virus vector in dogs with glycogen storage disease type Ia, Hum. Gene Ther. 23 (2012) 407-418.

[15] B. Crane, X. Luo, A. Demaster, K.D. Williams, D.M. Kozink, P. Zhang, T.T. Brown, C.R. Pinto, K. Oka, F. Sun, M.W. Jackson, L. Chan, D.D. Koeberl, Rescue administration of a helper-dependent adenovirus vector with long-term efficacy in dogs with glycogen storage disease type Ia, Gene Ther. 19 (2012) 443-452.

[16] D.D. Koeberl, C. Pinto, B. Sun, S. Li, D.M. Kozink, D.K. Benjamin Jr., A.K. Demaster, M.A. Kruse, V. Vaughn, S. Hillman, A. Bird, M. Jackson, T. Brown, P.S. Kishnani, Y.T. Chen, AAV vector-mediated reversal of hypoglycemia in canine and murine glycogen storage disease type Ia, Mol. Ther. 16 (2008) 665-672.

[17] D.A. Weinstein, C.E. Correia, T. Conlon, A. Specht, J. Verstegen, K. OnclinVerstegen, M. Campbell-Thompson, G. Dhaliwal, L. Mirian, H. Cossette, D.J. Falk, S. Germain, N. Clement, S. Porvasnik, L. Fiske, M. Struck, H.E. Ramirez, J. Jordan, K. Andrutis, J.Y. Chou, B.J. Byrne, C.S. Mah, Adeno-associated virus-mediated correction of a canine model of glycogen storage disease type Ia, Hum. Gene Ther. 21 (2010) 903-910.

[18] X. Luo, G. Hall, S. Li, A. Bird, P.J. Lavin, M.P. Winn, A.R. Kemper, T.T. Brown, D.D. Koeberl, Hepatorenal correction in murine glycogen storage disease type I with a double-stranded adeno-associated virus vector, Mol. Ther. 19 (2011) 1961-1970.

[19] K.J. Lei, H. Chen, C.J. Pan, J.M. Ward, B. Mosinger Jr., E.J. Lee, H. Westphal, B.C. Mansfield, J.Y. Chou, Glucose-6-phosphatase dependent substrate transport in the glycogen storage disease type-1a mouse, Nat. Genet. 13 (1996) 203-209.

[20] P.S. Kishnani, Y. Bao, J.Y. Wu, A.E. Brix, J.L. Lin, Y.T. Chen, Isolation and nucleotide sequence of canine glucose-6-phosphatase mRNA: identification of mutation in puppies with glycogen storage disease type Ia, Biochem. Mol. Med. 61 (1997) 168-177.

[21] D. Fleenor, R. Arumugam, M. Freemark, Growth hormone and prolactin receptors in adipogenesis: STAT-5 activation, suppressors of cytokine signaling, and regulation of insulin-like growth factor I, Horm. Res. 66 (2006) 101-110.

[22] R. Arumugam, D. Fleenor, M. Freemark, Lactogenic and somatogenic hormones regulate the expression of neuropeptide $\mathrm{Y}$ and cocaine- and amphetamineregulated transcript in rat insulinoma (INS-1) cells: interactions with glucose and glucocorticoids, Endocrinology 148 (2007) 258-267.

[23] K. Dheda, J.F. Huggett, S.A. Bustin, M.A. Johnson, G. Rook, A. Zumla, Validation of housekeeping genes for normalizing RNA expression in real-time PCR, Biotechniques 37 (2004) 112-114, (116, 118-119).

[24] R. Arumugam, D. Fleenor, D. Lu, M. Freemark, Differential and complementary effects of glucose and prolactin on islet DNA synthesis and gene expression, Endocrinology 152 (2011) 856-868.

[25] B. Sun, H. Zhang, L.M. Franco, S.P. Young, A. Schneider, A. Bird, A. Amalfitano, Y.T. Chen, D.D. Koeberl, Efficacy of an adeno-associated virus 8-pseudotyped vector in glycogen storage disease type II, Mol. Ther. 11 (2005) 57-65.

[26] D. Laflamme, Development and validation of a body condition score system for dogs, Canine Pract. 22 (1997) 10-15.

[27] Y. Yamazaki, M. Yuguchi, S. Kubota, K. Isokawa, Whole-mount bone and cartilage staining of chick embryos with minimal decalcification, Biotech. Histochem. 86 (2011) 351-358.

[28] T.I. Cesena, T.X. Cui, G. Piwien-Pilipuk, J. Kaplani, A.A. Calinescu, J.S. Huo, J.A. Iniguez-Lluhi, R. Kwok, J. Schwartz, Multiple mechanisms of growth hormoneregulated gene transcription, Mol. Genet. Metab. 90 (2007) 126-133.
[29] Y.-T. Chen, Glycogen storage diseases, in: C.T. Scriver, A.L. Beaudet, W.S. Sly, D. Valle (Eds.), The Metabolic and Molecular Bases of Inherited Disease, McGraw-Hill, New York, 2001.

[30] A. Katsurada, N. Iritani, H. Fukuda, Y. Matsumura, N. Nishimoto, T. Noguchi, T. Tanaka, Effects of nutrients and hormones on transcriptional and posttranscriptional regulation of fatty acid synthase in rat liver, Eur. J. Biochem./FEBS 190 (1990) 427-433.

[31] K.A. Greer, L.M. Hughes, M.M. Masternak, Connecting serum IGF-1, body size, and age in the domestic dog, Age 33 (2011) 475-483.

[32] L. Jaillardon, L. Martin, P. Nguyen, B. Siliart, Serum insulin-like growth factor type 1 concentrations in healthy dogs and dogs with spontaneous primary hypothyroidism, Vet. J. 190 (2011) e95-e99.

[33] C. Le Stunff, A.M. Gronowski, P. Rotwein, Contrasting acute in vivo nuclear actions of growth hormone and prolactin, Mol. Cell. Endocrinol. 121 (1996) 109-117.

[34] O. Torring, B. Isberg, H.E. Sjoberg, E. Bucht, A.L. Hulting, Plasma calcitonin, IGF-I levels and vertebral bone mineral density in hyperprolactinemic women during bromocriptine treatment, Acta Endocrinol. 128 (1993) 423-427.

[35] D. Fleenor, J. Oden, P.A. Kelly, S. Mohan, S. Alliouachene, M. Pende, S. Wentz, J. Kerr M. Freemark, Roles of the lactogens and somatogens in perinatal and postnatal metabolism and growth: studies of a novel mouse model combining lactogen resistance and growth hormone deficiency, Endocrinology 146 (2005) 103-112.

[36] B.A. Scheven, N.J. Hamilton, Longitudinal bone growth in vitro: effects of insulin-like growth factor I and growth hormone, Acta Endocrinol. 124 (1991) 602-607.

[37] J.D. Hanna, F. Santos, J.W. Foreman, J.C. Chan, V.K. Han, Insulin-like growth factorgene expression in the tibial epiphyseal growth plate of growth hormone-treated uremic rats, Kidney Int. 47 (1995) 1374-1382.

[38] R.C. Olney, J. Wang, J.E. Sylvester, E.B. Mougey, Growth factor regulation of human growth plate chondrocyte proliferation in vitro, Biochem. Biophys. Res. Commun. 317 (2004) 1171-1182.

[39] J. Wang, J. Zhou, C.A. Bondy, Igf1 promotes longitudinal bone growth by insulin-like actions augmenting chondrocyte hypertrophy, FASEB J. 13 (1999) 1985-1990.

[40] F. Long, K.S. Joeng, S. Xuan, A. Efstratiadis, A.P. McMahon, Independent regulation of skeletal growth by Ihh and IGF signaling, Dev. Biol. 298 (2006) 327-333.

[41] C. Trivin, J.C. Souberbielle, G. Aubertin, E. Lawson-Body, L. Adan, R. Brauner, Diagnosis of idiopathic growth hormone deficiency: contributions of data on the acid-labile subunit, insulin-like growth factor (IGF)-I and-II, and IGF binding protein-3, J. Pediatr. Endocrinol. Metab. 19 (2006) 481-489.

42] S. Cianfarani, A. Liguori, S. Boemi, M. Maghnie, L. Iughetti, M. Wasniewska, M.E. Street, S. Zucchini, G. Aimaretti, D. Germani, Inaccuracy of insulin-like growth factor (IGF) binding protein (IGFBP)-3 assessment in the diagnosis of growth hormone $(\mathrm{GH})$ deficiency from childhood to young adulthood: association to low $\mathrm{GH}$ dependency of IGF-II and presence of circulating IGFBP-3 18-kilodalton fragment, J. Clin. Endocrinol. Metab. 90 (2005) 6028-6034.

[43] E. Ferrante, C. Giavoli, S. Porretti, E. Vassallo, C.L. Ronchi, A.G. Lania, P. Beck-Peccoz, A Spada, Evaluation of the components of the insulin-like growth factors system in GH-deficient adults: effects of twelve-month rhGH treatment, Horm. Metab. Res. 38 (2006) 352-355.

[44] D.B. Dunger, A.T. Holder, J.V. Leonard, J. Okae, M.A. Preece, Growth and endocrine changes in the hepatic glycogenoses, Eur. J. Pediatr. 138 (1982) 226-230.

[45] T. Zoetis, M.S. Tassinari, C. Bagi, K. Walthall, M.E. Hurtt, Species comparison of postnatal bone growth and development, Birth Defects Res. B Dev. Reprod. Toxicol. 68 (2003) 86-110.

[46] B. Clancy, R.B. Darlington, B.L. Finlay, Translating developmental time across mammalian species, Neuroscience 105 (2001) 7-17.

[47] L.E. Case, D.D. Koeberl, S.P. Young, D. Bali, S.M. DeArmey, J. Mackey, P.S. Kishnani, Improvement with ongoing Enzyme Replacement Therapy in advanced lateonset Pompe disease: a case study, Mol. Genet. Metab. 95 (2008) 233-235.

[48] W.H. Yiu, Y.M. Lee, W.T. Peng, C.J. Pan, P.A. Mead, B.C. Mansfield, J.Y. Chou, Complete normalization of hepatic G6PC deficiency in murine glycogen storage disease type la using gene therapy, Mol. Ther. 18 (2010) 1076-1084. 